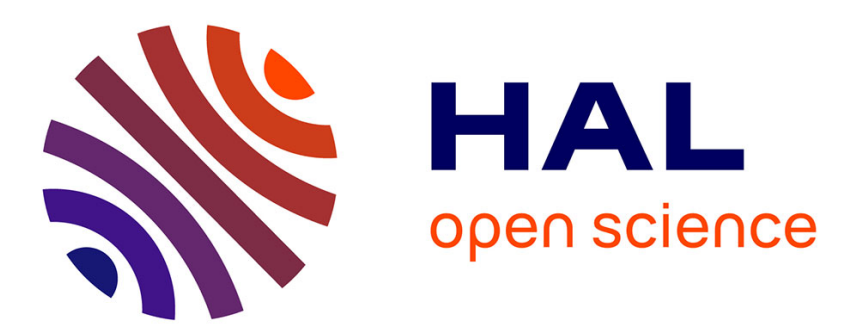

\title{
Experimental investigation and process optimization of the ultrasonic welding applied to papers
}

Q Charlier, J Viguié, B Harthong, J.-B -b Toni, M Terrien, D Imbault, Robert Peyroux

\section{- To cite this version:}

Q Charlier, J Viguié, B Harthong, J.-B -b Toni, M Terrien, et al.. Experimental investigation and process optimization of the ultrasonic welding applied to papers. Materials Science and Engineering Technology / Materialwissenschaft und Werkstofftechnik, 2021, 52, pp.891 - 906. 10.1002/mawe.202100031 . hal-03324046

\section{HAL Id: hal-03324046 https://hal.science/hal-03324046}

Submitted on 12 Dec 2021

HAL is a multi-disciplinary open access archive for the deposit and dissemination of scientific research documents, whether they are published or not. The documents may come from teaching and research institutions in France or abroad, or from public or private research centers.
L'archive ouverte pluridisciplinaire HAL, est destinée au dépôt et à la diffusion de documents scientifiques de niveau recherche, publiés ou non, émanant des établissements d'enseignement et de recherche français ou étrangers, des laboratoires publics ou privés. 


\title{
Experimental investigation and process optimization of the ultrasonic welding applied to papers
}

\section{Experimentelle Untersuchung und Prozessoptimierung von Ultraschallschweißen von Papier}

\author{
Q. Charlier ${ }^{1}$, J. Viguié2 ${ }^{2}$ B. Harthong ${ }^{1}$, J.-B. Toni ${ }^{1}$, M. Terrien ${ }^{3}$, \\ D. Imbault ${ }^{1}$, R. Peyroux ${ }^{1}$
}

Ultrasonic welding is a serious candidate in the development of methods to assemble papers and paperboards without using additional substances. However, the ultrasonic welding of papers remains a technological challenge considering the low weldability of lignocellulosic materials. This study aims to investigate on the ultrasonic welding process applied to papers in order to identify the processing conditions which favor the formation of strong welded joints. To reach such purpose, an experimental strategy was developed by combining the characterization of welded materials and the monitoring of process parameters. Experimentations were performed using a reference paper displaying a good weldability to specifically highlight the contribution of process parameters. Results indicate that the process is highly sensitive to vibration amplitude, power supplied by the high frequency generator, and sample thickness. Power seems to be a reliable indicator of the severity of the process. A strong decrease in the strength of the welded joints is observed when working with low thicknesses. It seems that the layers coated on top of papers are the main part of the material contributing in the development of adhesion at the welding joint. Overall, instrumenting the device has led to a better understanding of the ultrasonic welding of papers.

Keywords: Ultrasonic welding / paper / paperboard / process optimization / experimentation / instrumentation

Schlüsselwörter: Ultraschallschweißen / Papier / Pappe / Prozessoptimierung / Versuchsdurchführung / Instrumentierung

\section{Introduction}

Ultrasonic welding is a processing method to assemble materials by applying high-frequency acoustic vibrations under pressure. It presents many advantages: high processing speed, no need for additional substances, quite easy to automate, lo-

1 Université Grenoble Alpes, Grenoble INP, CNRS UMR 5521, 3SR, 38000 GRENOBLE, FRANCE

2 Centre Technique du Papier (CTP), 38044 GRENOBLE, FRANCE

3 Université Grenoble Alpes, Grenoble INP, CNRS UMR 5518, LGP2, 38000 GRENOBLE, FRANCE calized heating generated directly at the welding interface. It is already used at the industrial scale to weld thermoplastic polymers. Ultrasonic welding of thermoplastics has been studied for 40 years through experiments and modelling [1-4]. Today, it is known that heating is heterogeneous and that it results from two consecutive mechanisms [5]. First,

Corresponding author: Q. Charlier, Université Grenoble Alpes, Grenoble INP, CNRS UMR 5521, 3SR, 38000 GRENOBLE, FRANCE, E-Mail: quentin.charlier@3sr-grenoble.fr 
the heat is generated in localized area through interface friction mechanism. It is associated to interfacial pressure, amplitude of sliding, and the friction coefficient [6]. The resulting heat, called interface friction heating, is predominant until the glass transition temperature or the fusion temperature is reached (depending on the nature of the thermoplastic matrix). Then, the heat is generated by viscous dissipation (or viscoelastic heating) and spreads from localized areas to all the welding surface. This mechanism produces almost all the energy required to perform the welding. It is tightly related to the strain amplitude and the loss modulus of the welded material [6]. Energy directors are commonly used to focus ultrasonic energy and enable the triggering of interface friction heating in localized areas. In the case of thermoplastics, energy directors generally consist in extra amounts of polymer shaped in triangular beads and deposited on the surface of the material.

Among the recent contributions on the ultrasonic welding of thermoplastic polymers and composites, investigations have been performed on the welding kinetics through experimental approaches. It seems that the process can be described in five stages $[7,8]$. The welder data can be used to monitor the process and reach optimum performances. Moreover, the geometry of energy directors can also influenced the welding performances of fiberreinforced thermoplastics composites [9]. Several studies were also dedicated to modelling the ultrasonic welding process applied to thermoplastic polymers [10-12]. Strong models were developed integrating the coupling of thermo-mechanical and flowing material properties, as well as the changes of state and form of the material during the process [10]. Then, these models were used in order to discuss the influence of various process-related parameters to the welding performances of thermoplastics [12]. Results indicate that the ultrasonic welding of thermoplastics is a complex problem that needs to be handled at at least two magnitudes and on both time and space scales (s, $\mu \mathrm{s}$, and $\mathrm{m}, \mu \mathrm{m})$ [11]. Another interesting recent work discusses a method based on numerical analyses to simulate the effect of energy directors by adjusting the geometry of horn and anvil [6]. To this day, there is no global model delivering the suitable machine design and acoustic sizing according to the specificities of the thermoplastic parts to be welded, and conversely.
Today, ultrasonic welding also appears as a possible alternative to the use of oil-based adhesives to assemble papers and paperboards. Efforts are in part motivated by the close chemical nature between thermoplastic polymers and lignocellulosic materials. However, the use of welding processes based on applying acoustic vibrations under pressure to assemble wood or paper was not much studied so far. The first and only studies on this subject were done 10-15 years ago on the vibrational welding of wood, showing that it is possible to assemble wood by vibrational welding [13-18]. A lot of analyzing methods were used to understand the establishment of the welding joint: x-ray tomography, IR thermography, and NMR and IR spectroscopy [1517]. Results have highlighted some correlation between welding parameters and mechanical performances of welded joints [18]. Adhesion in wood pieces was found to originate from two main phenomena:

- A thermoplastic mechanism, caused by the flowing of the amorphous polymers of wood (hemicelluloses, lignin, and amorphous cellulose) when the temperature rises above their glass transition temperature. Wood polymers fill the voids in between fibers to create a structure similar to fiber-reinforced composites. This phenomenon leads to higher densities in the interfacial region (or interphase) [15].

- A thermosetting mechanism, consecutive to the thermoplastic one as it requires an intimate contact between wood components. Above $200{ }^{\circ} \mathrm{C}$, degradation reactions such as polysaccharide and lignin hydrolysis can occur creating isolated monomers. The condensation of the latter can result in the formation of new compounds, locally reinforcing the matrix and/or creating chemical bonding between phases which were initially separated [17].

Some numerical studies were also conducted on the modelling of the vibrational welding of wood mostly to predict the temperature during the process [19]. But the first models were very simple: vibration, chemical reaction, wood structure, mass transport were not considered. Recently, a hygrothermo-mechanical model was developed to describe the behavior of wood and used to study wood welding [20,21]. This strong predicting model integrates the porous and multi-components structure of wood, as well as heat and mass trans- 
port during the process. So far, it is the most accurate work on the subject.

To this day, only one research paper on the ultrasonic welding of paper-like materials has been reported so far [22]. It showed that raw papers can be welded only for high lignin and hemicelluloses contents in the paper pulp. Structural analyses have revealed that the establishment of adhesion in welded papers originates from a thermoplastic mechanism similar to the one described earlier. However, the degradation of paper also seems mandatory to generate adhesion which indicates that thermosetting mechanisms must also contribute. Nevertheless, most of papers and paperboards used today are coated with various layers to reach the properties required for their application (starch for strength, mineral pigments and latex binders for printability, polyvinyl alcohol for barrier properties, and so on...). Thus, the phenomena intervening in the ultrasonic welding of $100 \%$ lignocellulosic materials may not be representative of what happens when welding papers in general.

Nevertheless, much remains to be done to develop the knowledge on the acoustic welding of papers and paperboards. In particular, two main interconnected issues can be raised:

- How can we optimize the ultrasonic welding process applied to papers and paperboards (considering that the weldability of the material is known)? Indeed, thermoplastics are highly responsive to welding processes in general, meaning that they probably can be assembled by ultrasonic welding for a large (and not necessarily optimized) range of processing conditions. Process optimization may require more resources for papers compared to thermoplastics.

- What should be the properties of papers and paperboards to favor weldability (considering that they can be assembled in optimized conditions)? Papers and paperboards can display a large range of surface compositions and coating weights. As a consequence, the weldability of papers is also expected to depend on surface characteristics.

In this frame, the main concern of this study is the optimization of the process applied to papers. To dissociate the contribution of process parameters from material properties, experimentations are performed using a reference paper whose weldability is known. It means that should the welded joints show lower mechanical properties than ex- pected, it will be imputed to unoptimized processing conditions. As this reference paper is meant for food packaging applications, the welding of papers must also be done in non-severe conditions: no degradation will be tolerated. This point differs from the previous study on the ultrasonic welding of $100 \%$ lignocellulosic papers where all adhesion mechanisms were considered, including the one leading to the degradation of paper.

To reach such a goal, an experimental operating method was developed. It consists in combining the characterization of welded materials and the monitoring of process parameters and material characteristics. The idea is to deduce the range of optimized processing conditions leading to strong properties of welding joints. Following this strategy, an instrumented machine dedicated to the ultrasonic welding of papers and paperboards was set-up in 3SR laboratory. The device was instrumented to allow the tracking of welder data and sample thickness during the process. Several anvils and anvil supports were manufactured to investigate on the effect of motion modes and welding areas. This instrumented machine was then used to investigate on the influence of process parameters on the mechanical performances of welded samples. The influence of key parameters (power, vibration amplitude, and paper thickness) are finally evaluated and discussed to emphasize the conditions allowing the welding of papers.

\section{Materials and methods}

\subsection{Materials}

The reference paper is a natural machine-glazed kraft paper of $80 \mathrm{~g} / \mathrm{m}^{2}$ (Terrana from Gascogne $\mathrm{Pa}$ pier) supplied by Centre Technique du Papier, Figure 1. It is a dense $\left(1.21 \mathrm{~g} / \mathrm{cm}^{3}\right)$ and high mechanical strength paper (tensile strength $8.26 \mathrm{kN} / \mathrm{m}$ and $4.00 \mathrm{kN} / \mathrm{m}$ in the fiber and transverse directions, respectively) suitable for food contact and presenting a clean and smooth surface. Paper reels were coated by Centre Technique du Papier with polyvinyl alcohol (PVOH F17, from Thaiprochemical) using TK Polymer's chromatogeny machine at $40 \mathrm{~m} / \mathrm{min}$ in a processing way close to soft tip blade coating. Polyvinyl alcohol was cooked at $11.2 \%$ and $35^{\circ} \mathrm{C}$ to fit the process viscosity requirements (330 


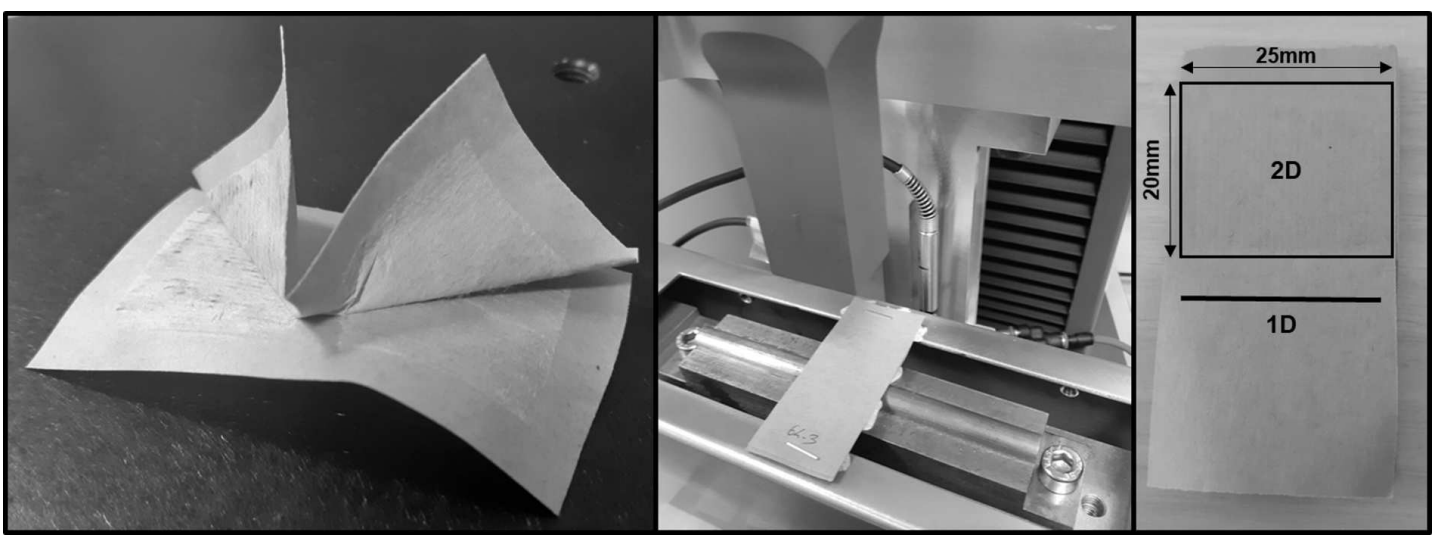

Figure 1. Partially peeled S1-S1 reference paper (left), setting up a paper sample onto the ultrasonic welder (center), and linear welding (1D) and welded surface (2D) obtained using the anvil $n^{\circ} 1$ and $n^{\circ} 2$, respectively (right).

$\mathrm{mPa} \cdot \mathrm{s})$. The amount of deposited polyvinyl alcohol is $2.7 \mathrm{~g} / \mathrm{m}^{2}$ on the topside (S1) and $0.5 \mathrm{~g} / \mathrm{m}^{2}$ on the backside (S2). The thickness of the coated paper is close to $100 \mu \mathrm{m}$.

As mentioned in the introduction, this paper was chosen on purpose to fit the objective of this study: understanding the contribution of process components in the ultrasonic welding applied to papers. Thus, it is accepted that:

- S1 papers present a very good weldability.

- S2 papers show a low weldability.

- Uncoated papers cannot be welded.

Regarding the processing method, it seems important to have some knowledge about the mechanical properties and the viscoelastic behavior of this reference paper in the thickness direction. However, it is not that simple to find an appropriate experimental strategy for this purpose considering that standard devices are not designed to assess high rigidity materials at ultrasonic frequencies. As far as we know, not much has been reported on the subject but we are currently working on it.

\subsection{Ultrasonic welding}

An ESW ultrasonic welder supplied by Sonimat was used to assemble papers, Figure 2. The welding machine is an electromechanical press equipped with a $2000 \mathrm{~N}$ force sensor and an acoustic apparatus connected to a $20 \mathrm{kHz}$ high frequency generator. The acoustic apparatus is mounted on the mobile crosshead whereas the anvil and its support are mounted on the base of the machine. A con- troller, located on the column of the press, allows the operator to set-up the welding parameters.

The acoustic apparatus is composed of a sonotrode/horn (surface $20 \times 25 \mathrm{~mm}^{2}$ ), a booster (gain 2.0), and a piezoelectric converter (CR 20), Figure 3. It was designed and manufactured by Sonimat considering the aimed application. The peakto-peak amplitude of the acoustic vibration is $92 \mu \mathrm{m}$. The amplitude can also be adjusted on the controller from $60 \%$ to $100 \%$ of its maximum.

We chose to work with mobile anvils. This means the anvil is not fixed on the base but attached to a support (or tooling) which allows the anvil to move in one direction (the crosshead axis). We consider this configuration to be the best to weld thin materials such as papers. In the frame of this study, experiments were done using two anvils $\left(\mathrm{n}^{\circ} 1\right.$ and $\mathrm{n}^{\circ} 2$ ) and two mobile supports (spring and cylinder), Figures 2,3 . The anvil $n^{\circ} 1$, supplied by Sonimat, is a cylindrical surface of radius $5 \mathrm{~mm}$. This shape is necessary to avoid sharp angles which can damage paper samples. It leads to linear (1D) weldings of $25 \mathrm{~mm}$-length, Figure 1 (approximate width $1 \mathrm{~mm}$ ). The anvil $\mathrm{n}^{\circ} 2$, supplied by Sonimat, is a flat surface machined to obtain $0.5 \mathrm{~mm}$-grooves separated from each other by $0.5 \mathrm{~mm}$-gaps. It produces a welding area of $20 \times 25 \mathrm{~mm}^{2}$ (2D), Figure 1 . The spring tooling, designed by our team, is composed of two V-shaped leaf springs fixed on the base of the machine. The anvil is mounted on the top of the springs (equivalent stiffness of the apparatus $=800 \mathrm{~N} / \mathrm{mm}$ ). The cylinder tooling, supplied by Sonimat, is composed of 3 pneumatic cylinders on which the anvil is fixed. Cylinders are 


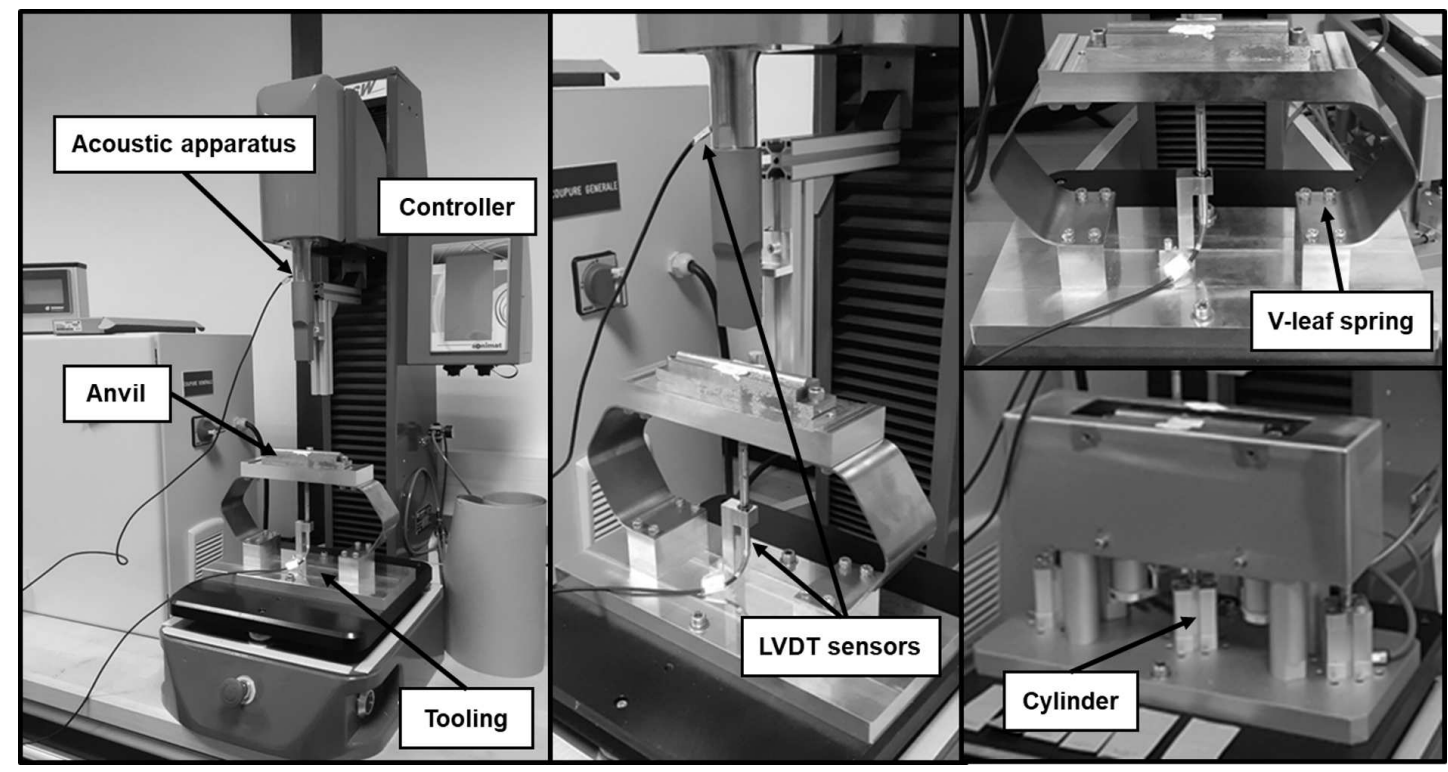

Figure 2. Instrumented ultrasonic welding machine (left and center), spring tooling (upper right), and cylinder tooling (lower right).

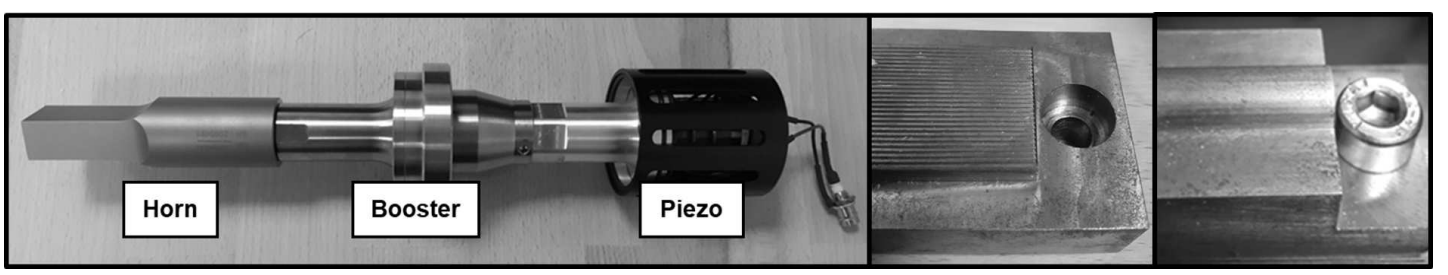

Figure 3. Components of the ultrasonic welding machine, from left to right: acoustic apparatus, anvil $n^{\circ} 2$, and anvil $n^{\circ} 1$.

connected to a compressed air network ( 7 bar). The force required to set the cylinders in motion can be adjusted by using a pressure relief valve ( 2 bar to 6 bar). Three sets of cylinders (ADN 20, ADN 32, ADN 40, from Festo) were used to cover a wider range of forces.

The welding procedure is programmed on the controller from the four parameters recorded by the machine: time, power delivered by the high frequency generator, force applied by the crosshead, and crosshead displacement. The operator can choose the motion mode (force or speed), the end condition (time, distance, or energy), the welding velocity, the amplitude, and whether to apply a post-welding load. All these inputs must be adapted to the properties of the welded materials and the tooling set-up.

To perform the welding, paper samples are stapled, placed on the anvil, and maintained with adhesive paste, Figure 1. This is necessary to avoid paper slipping leading to inefficient weldings. The machine then calibrates the positions by performing a mechanical zero at a force of 20 daN. Finally, ultrasonic weldings are carried out at $23 \pm 2{ }^{\circ} \mathrm{C}$ and $45 \pm 5 \%$ of relative humidity. Ultrasonic vibrations are always triggered before the contact between horn and anvil at $0.5 \mathrm{~mm}$ (cylinder tooling) and $1.5 \mathrm{~mm}$ (spring tooling) above the mechanical zero.

\subsection{Instrumentation of the ultrasonic welder}

The ESW ultrasonic welder is designed for industrial needs. As a consequence, the exportation of welding data is initially not possible. To fit academic research needs, a NI 6361 acquisition device was connected to the ultrasonic welder to acquire the data recorded by the machine during the process. The acquisition card possesses 16 analog and 24 digital inputs and can acquire up to a frequency 
of $2 \mathrm{MHz}$ for a single channel. Recorded data (force, power, and amplitude signals) are sent to an external computer via a LabVIEW program. The LabVIEW interface also displays the evolution of process parameters during the welding. However, the displacement recorded by the machine (calculated from the rotation of the screw inside the column) can not be exported.

Two linear variable differential transformer displacement sensors (Orbit DP/10/S, from Solartron) were also integrated to the machine. The objective is to follow the displacement of the crosshead and the anvil, as well as and the changes in sample thickness during the welding. The sensors have a range of $10 \mathrm{~mm}$ for a precision and repeatability close to $1 \mu \mathrm{m}$. In order to track sample thickness, one sensor is positioned to measure the relative displacement between crosshead and anvil. The other one measures the absolute position of either the crosshead (spring tooling) or the anvil (cylinder tooling). Displacement data are recorded at a frequency of $4000 \mathrm{~Hz}$ and processed through the acquisition card and LabVIEW program described earlier.

\subsection{Methodology}

To investigate on the effect of processing conditions, reference papers were welded using different sets of machine parts and process control inputs, Table 1. As detailed further, machine parts refer to acoustic parts, anvil, and anvil supports while process control inputs consider all the parameters set by the operator on the controller. Preliminary studies performed ahead of the ones presented in this paper have shown that the most influencing parameters are force and amplitude. However, these two inputs are also indirectly related: changing the force or the amplitude modifies the amount of power supplied by the high frequency generator. As detailed further, investigations have highlighted that power is in fact the key indicator. In the end, we decided to design most of the experiments by aiming for a process output: the power peak $\left(P_{m}\right)$. It was done by changing the welding force while keeping a constant vibration amplitude. Unless it is specifically indicated otherwise in the result section, the following set of default parameters were used to weld the reference paper:

Table 1. Summary of all the various items which have been investigated in the frame of this study on the effects of processing conditions on the ultrasonic welding of papers.

\begin{tabular}{|c|c|c|}
\hline US welding components & Item & Value \\
\hline \multirow[t]{3}{*}{ Machine parts } & Anvil & $\mathrm{N}^{\circ} 1, \mathrm{~N}^{\circ} 2$ \\
\hline & Anvil support & Cylinder, spring \\
\hline & Cylinder & ADN 20, 32 and 40 \\
\hline \multirow[t]{8}{*}{ Process control inputs } & Motion mode & $\begin{array}{l}\text { Velocity-control (cylinder) } \\
\text { Force-control (spring) }\end{array}$ \\
\hline & Force (spring) & $25-45-55-65-85-105$ daN \\
\hline & Air pressure (cylinder) & 2 bar to 6 bar (adjusted to reach aimed power) \\
\hline & Amplitude & $60-75-80-90-100 \%$ \\
\hline & Energy end condition & $\begin{array}{l}10-20-50-70-100-110-145 \mathrm{~J}\left(\mathrm{~N}^{\circ} 1\right) \\
250 \mathrm{~J}\left(\mathrm{~N}^{\circ} 2\right)\end{array}$ \\
\hline & Welding velocity & $1 \mathrm{~mm} / \mathrm{s}$ (cylinder), $2 \mathrm{~mm} / \mathrm{s}$ (spring) \\
\hline & Post-welding load & Welding force (cylinder), Set force (spring) \\
\hline & Post-welding load time & $0.1-1-10 s-1-10 s$ \\
\hline Material characteristics & Paper thickness & $0.2 \mathrm{~mm}-2 \mathrm{~mm}$ \\
\hline Welding outputs & Power & $\begin{array}{l}110-130-150-170-200-220 \mathrm{~W}\left(\mathrm{~N}^{\circ} 1\right) \\
475-675-825 \mathrm{~W}\left(\mathrm{~N}^{\circ} 2\right)\end{array}$ \\
\hline
\end{tabular}


- Motion mode: velocity (cylinder tooling), force (spring tooling).

- End condition: energy threshold.

- Welding velocity: $2.0 \mathrm{~mm} / \mathrm{s}$ (spring tooling), $1.0 \mathrm{~mm} / \mathrm{s}$ (cylinder tooling).

- Amplitude: $60 \%$.

- Post-welding load: force maintained constant at the end of the welding during $1 \mathrm{~s}$.

Additional details are reported further when needed in the result section.

\subsection{Welding performances}

T-peeling tests were performed to evaluate the mechanical performances of the welded papers using an Instron 5944 testing machine equipped with a 2 $\mathrm{kN}$ sensor at a displacement rate of $1 \mathrm{~mm} / \mathrm{s}$. Papers were peeled along the width of the welded joint and peeling forces per unit width were reported in $\mathrm{N} / \mathrm{m}$, Figure 4 . The force required to bend the studied papers is negligible compared the force needed to peel them. The peeling strengths used further to discuss mechanical performances refer to the peak force per unit width which corresponds to the failure of the welded joint. Mean strengths and standard deviations were calculated on 3 samples. Peeling tests were carried out at $23 \pm 2{ }^{\circ} \mathrm{C}$ and $45 \pm 5 \%$ of relative humidity.

\section{Results and discussion}

\subsection{Operating the ultrasonic welder}

As an introduction to the results and discussion section, the objectives of this part are:

- To highlight the various components of ultrasonic welding and their connection with the physical quantities involved in the process.

- To show how the type of tooling influences the process.

It is mandatory to detail these points first to allow a better understanding of the results presented further.

\subsubsection{Ultrasonic welding components and physical quantities}

Four main physical quantities are involved in ultrasonic welding:

- Frequency of the vibration. In most case, a high frequency generator can only work at one given frequency. Thus, the frequency is generally set when designing a welding machine. For this reason, the effect of frequency will not be investigated in this study.

- Vibration amplitude, which depends mainly on the characteristics of the acoustic apparatus. For

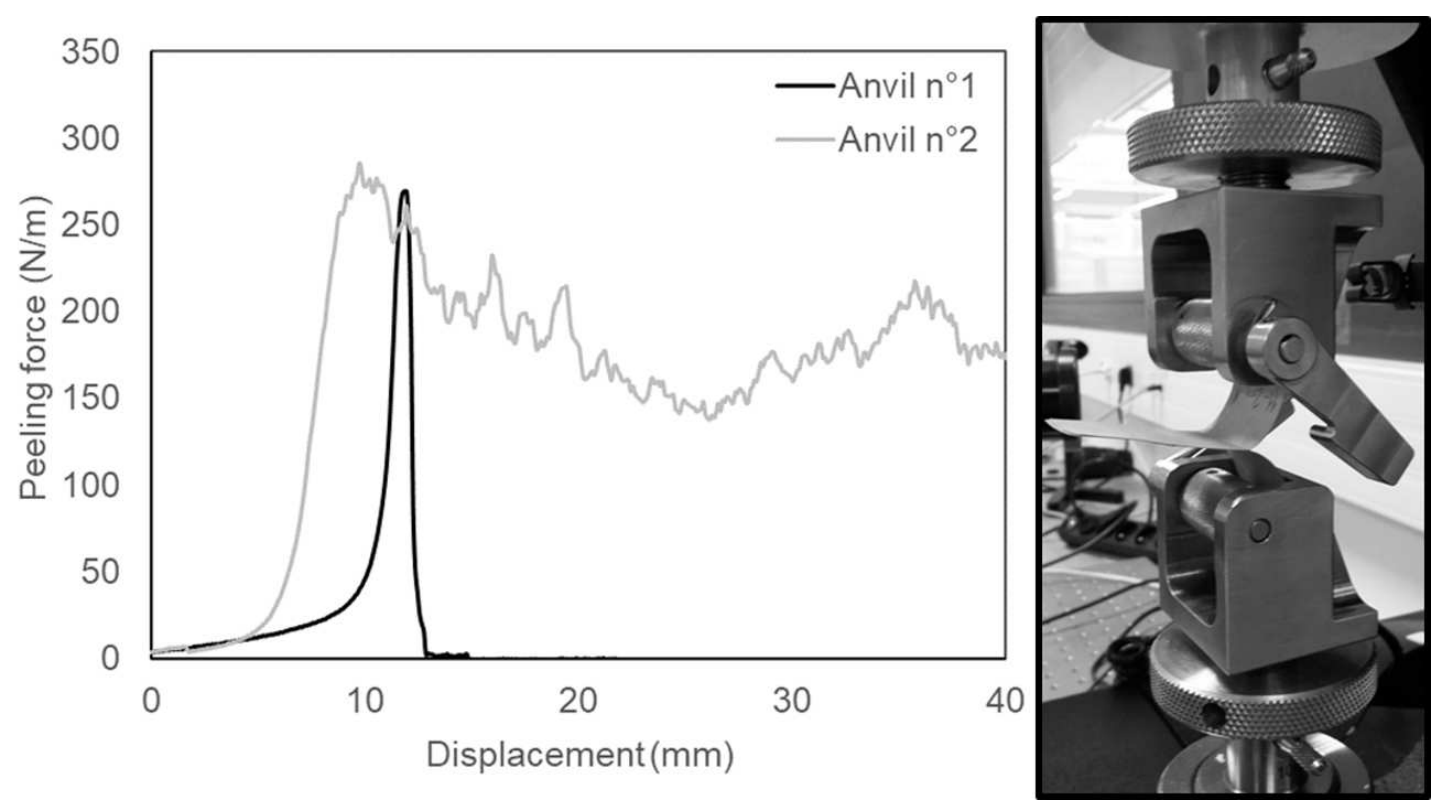

Figure 4. Peeling set-up to evaluate the performances of welded papers (right) and typical peeling curves of S1-S1 papers (left). 
a given apparatus, the amplitude can be adjusted by changing the booster. The welder also possesses a setting allowing the modification of the amplitude from the controller, Figure 5. To decrease the vibration amplitude, an algorithm commands the generator to use a working frequency slightly different from the resonance frequency. Therefore, the sonotrode does not vibrate at its full capability and lower vibration amplitudes are obtained.

- Pressure applied on the welded material, which depends on the force applied by the crosshead and the welding surface. The loading is also influenced by tooling type and characteristics, welding velocity, and material properties. Pressure is quite complex to deal with considering that gradients are voluntarily introduced to trigger heating via friction. Thus, materials assembled by ultrasonic welding are always subjected to a pressure field which is difficult to estimate. The simplest way to adjust the pressure remains by acting on the force applied by the crosshead.

- Power delivered by the high frequency generator, which depends on all the other physical quantities presented above considering that the mechanical work developed by the vibrating horn is the product of force by strain amplitude in a given amount of time. Consequently, the power peak increases linearly with the welding force for a given amplitude, Figure 6 . The power peak also increases with the amplitude for a given

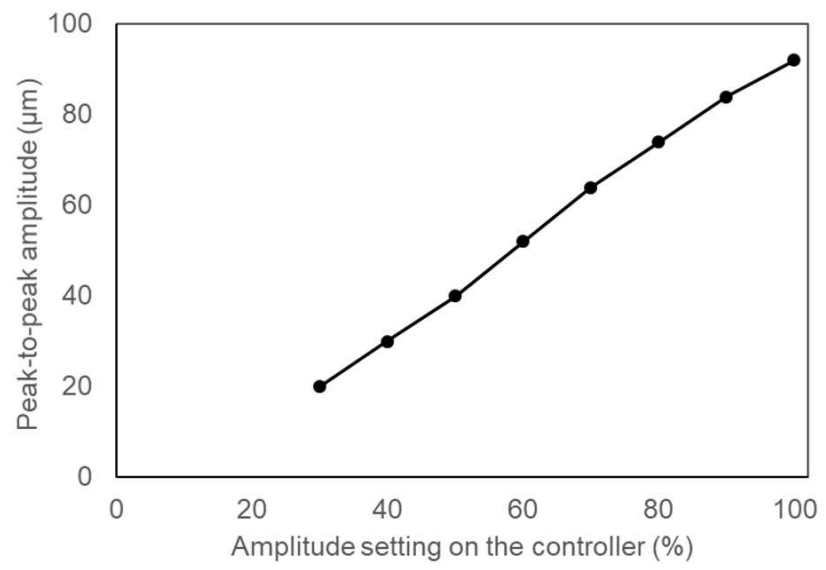

Figure 5. Sonotrode peak-to-peak amplitude measured when vibrating in the air for various amplitude settings on the controller (data supplied by Sonimat).

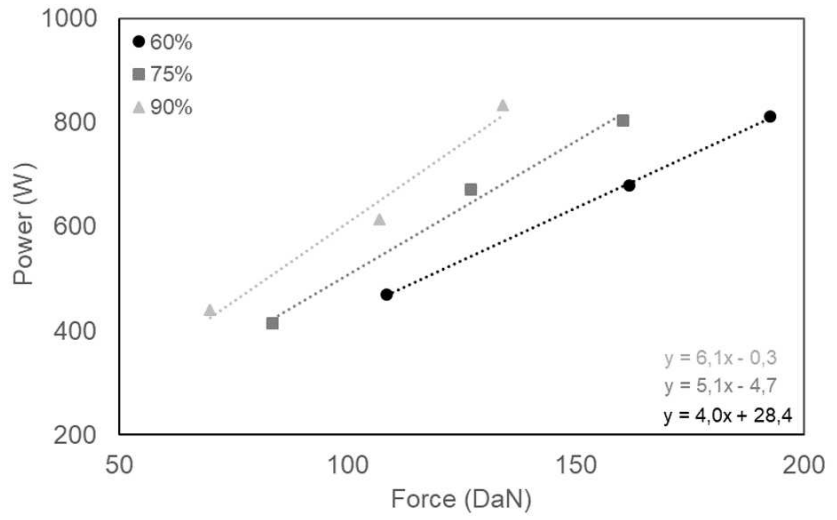

Figure 6. Peak power $\left(P_{m}\right)$ delivered by the high frequency generator versus maximal force applied by the crosshead for three vibration amplitudes (60-75-90\%) while welding the reference paper (S1-S1) using the cylinder tooling and the anvil $n^{\circ} 2$. Welding conditions: air pressure ( 2 bar to 6 bar) and cylinders (ADN 20, 32 and 40) were adjusted to reach 475-675-825 W with each amplitude, end condition $250 \mathrm{~J}$.

welding load, Figure 6 . The evolution of power in time during the welding also depends on tooling type and characteristics, welding velocity, and material properties. It is difficult to find favorable conditions to discuss the effect of power considering that the latter is an output depending on many other parameters. The best way to investigate on the effect of power seems to fix two of the three other physical quantities and modify the remaining one.

From an operating point of view however, the components intervening in the ultrasonic welding process can be classified in three categories, Table 1:

- Machine parts, which include the characteristics of the acoustic parts (vibration amplitude, horn surface, gain), and the type and characteristics of the anvil (welding surface, texture) and its support (fixed or mobile, cylinder or spring).

- Process control inputs, which consider the feedback variable in the control loop (force or velocity), nature of the end condition (time, distance, or energy), the post-welding load, the welding velocity, and the amplitude.

- Material characteristics, which include the weldability of the material, its core structure and mechanical properties, and its thickness.

The modification of different components might end up in having the same effect on the physical 
quantities. For example, the vibration amplitude results from the characteristics of acoustic parts but it can also be adjusted on the controller. As well, pressure applied on the welded material can be changed either by modifying the welding force or the horn surface.

Investigating on the effect of all these components and physical quantities is too much for the scope of one publication, especially when considering a new material with peculiar structure and properties. In this study, the focus is put on the influence of power, amplitude, and sample thickness on the mechanical performances of ultrasonic-welded papers using mainly process control inputs to change the welding conditions.

\subsubsection{Nature of anvil support}

The type of anvil support is the first element to consider when programming the welding procedure as it decides which motion mode must be used. Velocity-control is mandatory when using a cylinder tooling since the operating force is determined by the pressure inside the cylinders. Both force and velocity-control can be used with the spring tooling. However, force-control procedures are preferred in this case.

When using a cylinder tooling and a velocitycontrol procedure, the crosshead moves at a constant velocity from the triggering of ultrasonic vibrations until the end of the welding, Figure 7 . The anvil does not move until there is a contact between horn and anvil. Past the contact, crosshead and anvil move at the same velocity. As a consequence, the measured force goes immediately from $0 \mathrm{~N}$ to a maximal value $\left(F_{m}\right)$ corresponding to the force required to put the cylinders in motion, Figure $8 . F_{m}$ can be adjusted either by changing the cylinders or the air pressure. The evolution of power in time during the welding follows the same trend. First, power goes from $0 \mathrm{~W}$ to $30 \mathrm{~W}-50 \mathrm{~W}$ when ultrasonic vibrations are triggered. This value corresponds to the power consumption when the sonotrode vibrates in the air $\left(P_{a}\right)$. Then, power immediately increases from $P_{a}$ to a peak value $\left(P_{m}\right)$ when anvil and horn come into contact. Finally, it slightly decreases until reaching the end condition of the welding. One can observe that when the crosshead reaches the position of mechanical zero, the speed decreases for a short time, Figure 7. This is due to machine automation. As a consequence, a slight step can be observed in the force and power representations in time, Figure 8.

When using a spring tooling and a force-control procedure, the crosshead moves at a constant velocity from the triggering of ultrasonic vibrations until the set force is reached, Figure 7. Then, the crosshead stops and maintains its position until the end of the welding. The anvil does not move until contact between horn and anvil. Past the contact, crosshead and anvil advance at the same velocity. It must be noted that contact is made before the mechanical zero (performed at $20 \mathrm{daN}$ ). The force increases linearly from $0 \mathrm{~N}$ to the set value which is also the peak force $\left(F_{m}\right)$, Figure 8 . The loading de-
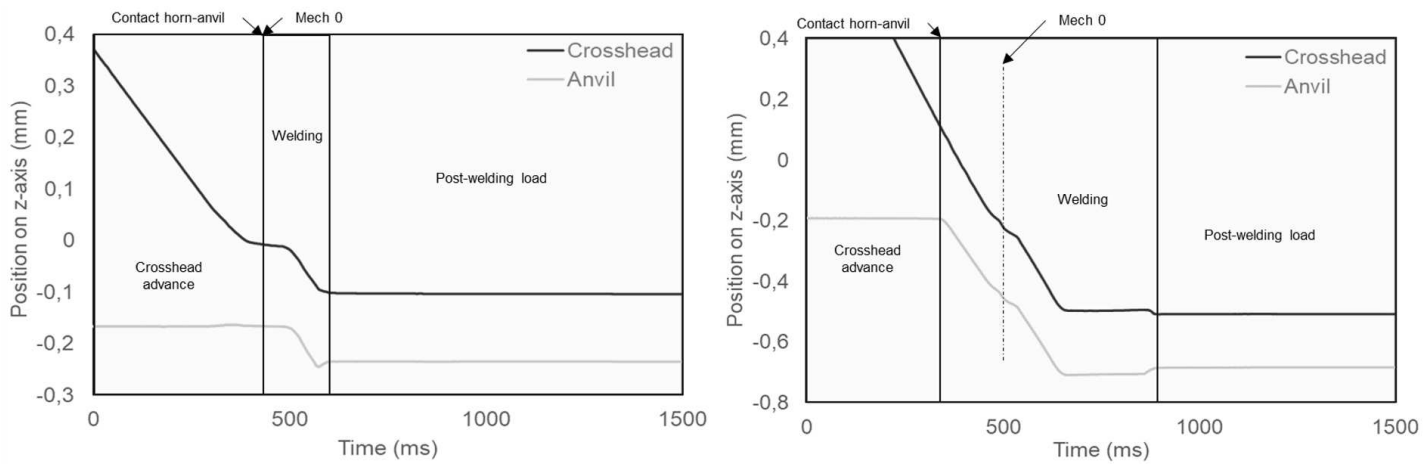

Figure 7. Anvil and crosshead displacements during the ultrasonic welding of S1-S1 papers on the anvil $\mathrm{n}^{\circ} 1$ using the cylinder (left) and the spring (right) toolings. Horn and anvil positions are distanced by paper thickness. Cylinder welding conditions: ADN 20 cylinders, air pressure 2 bar, end condition $10 \mathrm{~J}$. Spring welding conditions: set force 25 daN, end condition $25 \mathrm{~J}$. 

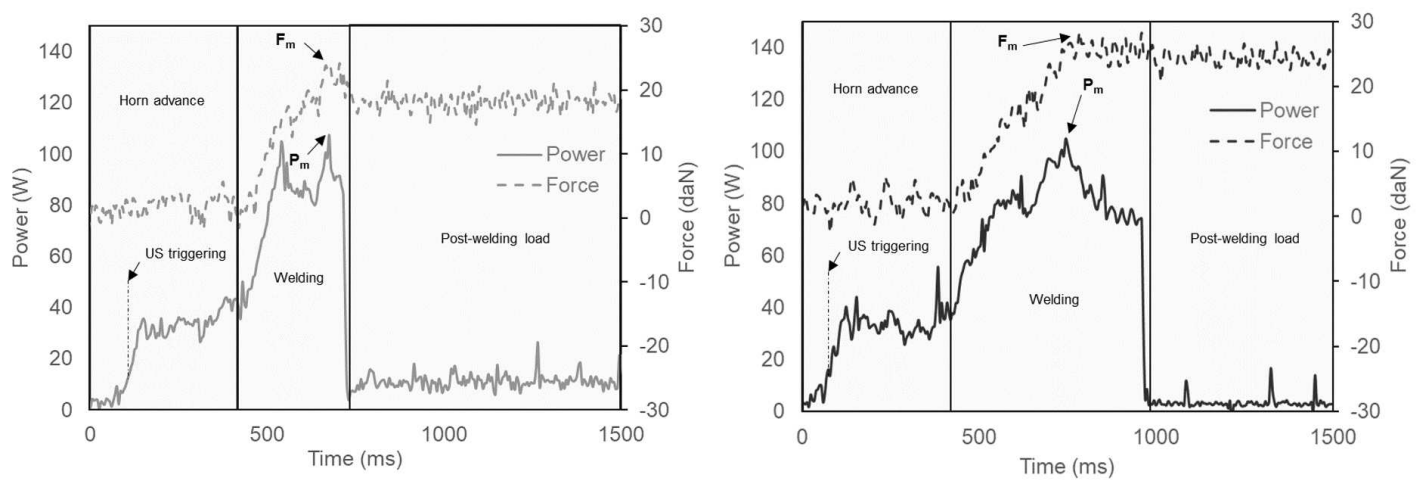

Figure 8. Force $(--)$ and power $(-)$ versus time during the ultrasonic welding of S1-S1 papers on the anvil $n^{\circ} 1$ using the cylinder (left) and the spring (right) toolings. Cylinder welding conditions: ADN 20 cylinders, air pressure 2 bar, end condition $10 \mathrm{~J}$. Spring welding conditions: set force $25 \mathrm{daN}$, end condition $25 \mathrm{~J}$

pends on spring stiffness and welding velocity. Power also increases linearly from $P_{a}$ to a power peak $\left(P_{m}\right)$ happening when the crosshead stops its motion. Then, power slightly decreases until reaching the end condition of the welding.

The main difference between the two types of tooling/procedure is the loading behavior. Using a cylinder tooling tends to reduce welding times but the procedure is more traumatic for machine parts. On the other hand, higher welding velocities can be used when working with the spring tooling. Despite those differences, the type of tooling does not affect much the mechanical performances of welded papers, Table 2. If the machine set-up and the process parameters are set to aim a same $F_{m}$, both cylinder and spring toolings show a close associated $P_{m}$ and welded papers display almost equivalent me-

Table 2. Peeling strength of papers assembled by ultrasonic welding on the anvil $\mathrm{n}^{\circ} 1$ using spring and cylinder toolings. $F_{m}$ and $P_{m}$ refer to the maximum load and power recorded during the welding. Cylinder welding conditions: ADN 20 cylinders, air pressure 2-4 bar, end condition $10 \mathrm{~J}$. Spring welding conditions: set force 25$45 \mathrm{daN}$, end condition 25-40 J.

\begin{tabular}{llllll}
\hline Welding conditions & \multicolumn{4}{c}{ Adhesion strength $(\mathrm{N} / \mathrm{m})$} \\
\hline Tooling & $F_{m}($ daN $)$ & $P_{m}(\mathrm{~W})$ & S1-S1 & S1-S2 & S2-S2 \\
Cylinder & 27.5 & 107 & $245 \pm 50$ & $107 \pm 29$ & 0 \\
& 46.3 & 142 & $274 \pm 7$ & $211 \pm 12$ & $34 \pm 7$ \\
Spring & 30.6 & 105 & $220 \pm 49$ & $40 \pm 23$ & 0 \\
& 50.4 & 130 & $250 \pm 14$ & $132 \pm 20$ & $8 \pm 2$ \\
\hline
\end{tabular}

chanical properties. The cylinder tooling shows a slightly higher $P_{m}$ for a given $F_{m}$ which is attributed to effects resulting from the faster loading. But it does not significantly affect the peeling strengths of welded papers, except for S1-S2 samples whose performances improve from $130 \mathrm{~W}$ to $140 \mathrm{~W}$.

At last, it must be pointed out that monitoring sample thickness was not successful for papers. It seems that displacement signals are highly affected by the interruption of ultrasonic vibrations which results in a $10 \mu \mathrm{m}$-magnitude change, Figure 7. However, it is possible to mechanically measure with high accuracy the thickness reduction by performing mechanical zeros before and after the welding.

\subsection{Influence of power}

Power seems to be one of the most important parameter of the ultrasonic welding procedure. When trying to weld papers with a too low $P_{m}$, samples are not assembled. Upon increasing $P_{m}$, papers can progressively be welded. In this range, the peeling strength increases with $P_{m}$ until reaching a maximum (maybe a plateau), Figure 9. The latter seems to depend on the weldability of the material: $250 \mathrm{~N} /$ $\mathrm{m}$ for $\mathrm{S} 1-\mathrm{S} 1,150 \mathrm{~N} / \mathrm{m}$ for S1-S2, and about $20 \mathrm{~N} / \mathrm{m}$ for S2-S2 samples. Failure propagation when peeling the welded joint is mostly adhesive at low $P_{m}$. It progressively changes to cohesive when $P_{m}$ increases and the peeling strength gets closer to the maximum value that can reach the material. Then, the welding process starts damaging the materials. 


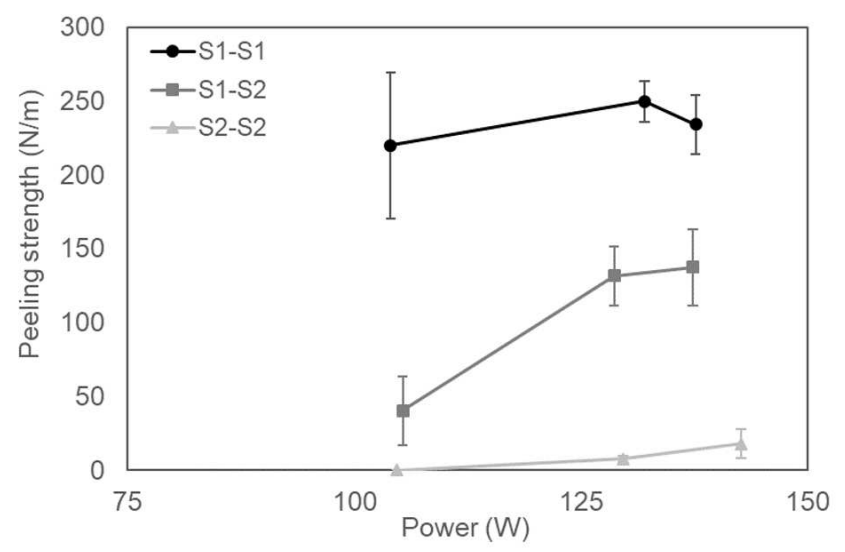

Figure 9. Peeling strength versus maximal power $\left(P_{m}\right)$ delivered by the high frequency generator for three samples welded using the spring tooling and the anvil $n^{\circ} 1$ (end conditions: $25-40-50 \mathrm{~J}) . P_{m}$ was adjusted by changing the set force (25-45-55 daN) in the welding procedure.

Partially burnt interfaces can be observed after peeling and the peeling strength starts decreasing. For too high $P_{m}$, papers are burnt and eventually destroyed. These experiments were performed at a fixed vibration amplitude. $P_{m}$ was adjusted by changing the set force in the welding procedure.

As mentioned in the physical quantities section, the shape of the power curve is influenced by welding parameters (tooling type, welding velocity, and so on). But it also depends a lot on the properties of the welded material. Indeed, experiments performed on different papers and paperboards have shown that each material display a specific power curve for a given welding procedure. It means that $P_{m}$ and power profile can change from one paper to another for identical process control inputs and ma- chine parts. When using the spring tooling and different set forces, the shape of the power curve remains the same until $P_{m}$ is reached, Figure 10. It gives an idea of the dependency between the set force and the power peak. However, the shape of the power curve is not influenced by the nature and the characteristics of paper coatings (as long as the coating weight is low enough compared to paper basis weight). It means that the power curve will remain the same when welding a same paper coated with different surface coatings, Figure 10. This observation involves strong outcomes. First, the ultrasonic welder only "sees" the core material: structure, mechanical properties, and thickness. The machine response when welding a material can be evaluated by observing the power curve. The latter describes how the material reacts to the ultrasonic welding procedure, i.e. how the material is capable to convert acoustic vibration into interfacial heat. Secondly, the weldability only results from surface properties (or coating characteristics), which does not affect in any way the process conduct. It means that the ultrasonic welder cannot differentiate S1S1 from S2-S2 paper joints despite the fact that they display different mechanical properties. Surface properties seem to dictate how the interfacial heat is able to develop adhesion at the welded joint. Thus, the successful ultrasonic welding of papers seems to be associated to a two-step condition: finding the optimized process parameters to efficiently convert acoustic vibration into interfacial heat, and finding the optimized coating properties to develop strong welded joints. It also means that paper only plays a role of support for the coated layer in the development of adhesion. In a way, the
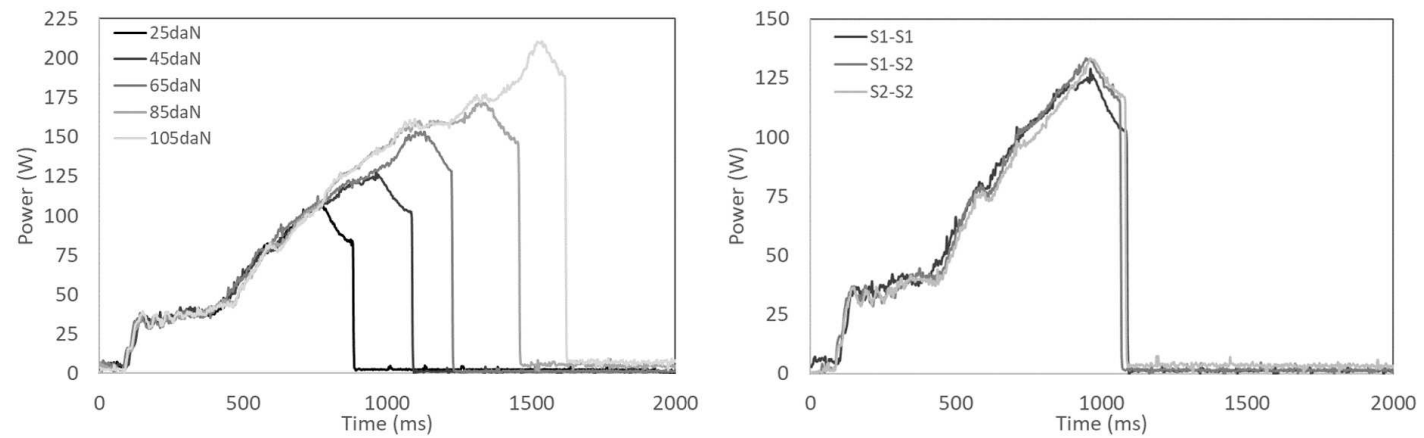

Figure 10. Power curves of S1-S1 samples welded using different set forces (left) and power curves of the three studied samples welded at $45 \mathrm{daN}$ (right) while using the spring tooling and the anvil $\mathrm{n}^{\circ} 1$. Spring welding conditions: set force $25-45-$ 65-85-105 daN, end condition 20-45-70-110-145 J. 
welding of papers is close to some hybrid weldings already reported in the literature, such as the ultrasonic welding of carbon-fiber reinforced epoxy based composites by introducing thermoplastic films at the welding interface [23]. These results confirm that it is really important to separate the contribution of process and materials to improve the knowledge on the ultrasonic welding of papers.

It seems that power profile and $P_{m}$ are accurate indicators of the severity of the welding. The latter could be defined by the amount of power per volume unit received by the welding interface. Previous works done on the vibrational welding of wood [15] and on the ultrasonic welding of papers [22] have shown that welded joints display higher densities than the initial material. In the case of papers, this densification tends to reduce the thickness at the welding joint. Thickness reduction measurements indicate that the thickness of welded samples decreases when $P_{m}$ increases, Table 3. For a set force of $25 \mathrm{daN}$, the thickness decreases of $20 \%-$ $25 \%$. When increasing the set force to $105 \mathrm{daN}$, the thickness reduction becomes larger (close to $35 \%-40 \%$ ) which suggests that the material was more affected by the welding process. It confirms that $P_{m}$ can inform the operator whether welding conditions are strong or moderate. Thus, a power monitoring could be used to facilitate the optimization of welding conditions. Moreover, a power-based strategy could also be used to control the level of performance of welded papers. Indeed, the weldability of various coatings could be quickly and efficiently evaluated by welding papers at the same $P_{m}$. Programing a device to perform powercontrol weldings could represent a great applicative interest regarding industrial prospects.

Table 3. Thickness reduction $(\Delta e)$ for $S 1-S 1$ samples welded using the spring tooling and the anvil $\mathrm{n}^{\circ} 1$ at different welding forces. $\Delta e$ was measured by performing mechanical zeros before and after the welding. $F_{m}$ and $P_{m}$ refer to the maximum load and power recorded during the welding. Spring welding conditions: set force 25-65105 daN, end condition 20-70-145 J.

\begin{tabular}{llll}
\hline$F_{m}(\mathrm{daN})$ & $P_{m}(\mathrm{~W})$ & $\Delta e(\mu \mathrm{m})$ & $\Delta e(\%)$ \\
\hline 25 & 107 & $42 \pm 9$ & $25 \pm 5$ \\
65 & 153 & $53 \pm 8$ & $32 \pm 5$ \\
105 & 205 & $58 \pm 4$ & $34 \pm 2$ \\
\hline
\end{tabular}

\subsection{Influence of vibration amplitude}

Welded papers seem to display better performances when welded at lower amplitudes, Table 4. While working with the anvil $\mathrm{n}^{\circ} 2$ and the cylinder tooling, the peeling strength increased from $40 \mathrm{~N} / \mathrm{m}$ to $90 \mathrm{~N} / \mathrm{m}$ when decreasing the amplitude from $100 \%$ to $60 \%$. To perform this experiment, pressure in the cylinders have been adapted to obtain an identical $P_{m}$ for all vibration amplitudes. As said earlier, it seems not fair to compare the mechanical performances of a same paper welded at different $P_{m}$ which could correspond to different amounts of power received by the welding interface.

Deeper investigations performed with the anvil $n^{\circ} 1$ have shown that the maximal performances reached by paper joints do not change with the amplitude. But the reproducibility of experiments is worse at $100 \%$ compared to $60 \%$, Figure 11 . Thus, the average and standard deviation calculations indicate that mechanical performances decrease when the amplitude setting is increased. However, another indicator based on the selection of the highest peeling strengths would show otherwise. It was reported in other works that low thicknesses can lead to larger standard deviations while working on the ultrasonic welding of polylactic acid films with similar vibration amplitudes $(65 \mu \mathrm{m}-80 \mu \mathrm{m})$ [24]. This inconsistency was attributed to the criticalness in horn/fixture alignment. Machine parts-related issues may indeed contribute. As will be detailed in next section, we think that material characteristics and in particular sample thickness is a critical point in this case.

Table 4. Peeling strength $(F / l)$ versus theoretical vibration amplitude (VA, from data supplied by Sonimat, Figure 5) for S1-S1 papers welded at different amplitude settings $(A S)$ using the cylinder tooling and the anvil $\mathrm{n}^{\circ} 2$. $F_{m}$ and $P_{m}$ refer to the maximum load and power recorded during the welding. Welding conditions: air pressure (2 bar to 6 bar) in cylinders ADN 32 was adjusted to reach $500 \mathrm{~W}$ with each amplitude, end condition $250 \mathrm{~J}$.

\begin{tabular}{lllll}
\hline$A S(\%)$ & $V A(\mu \mathrm{m})$ & $F_{m}(\mathrm{daN})$ & $P_{m}(\mathrm{~W})$ & $F / I(\mathrm{~N} / \mathrm{m})$ \\
\hline 100 & 92 & 61 & 465 & $36 \pm 11$ \\
80 & 74 & 81 & 506 & $58 \pm 7$ \\
60 & 52 & 107 & 498 & $89 \pm 12$ \\
\hline
\end{tabular}




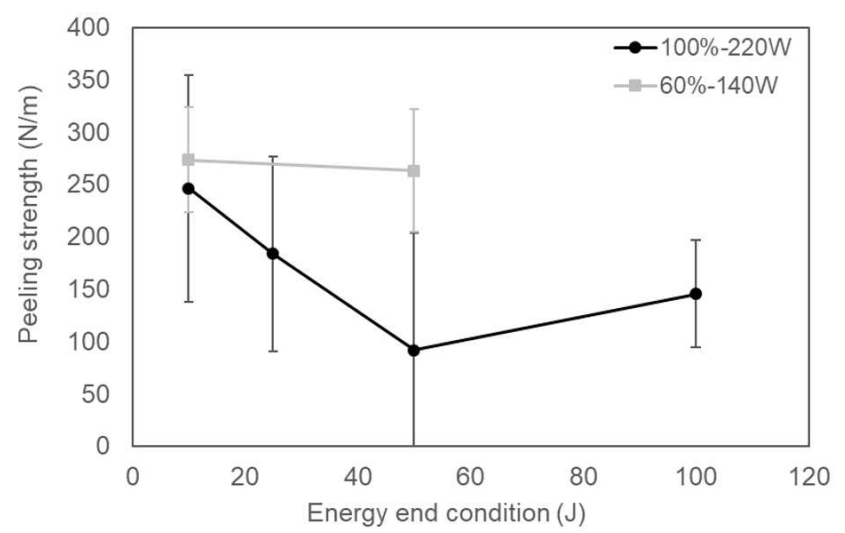

Figure 11. Peeling strength versus energy end condition for two $P_{m}(140 \mathrm{~W}$ and $220 \mathrm{~W})$ while welding the reference paper (S1-S1) using the cylinder tooling and the anvil $n^{\circ} 1$. Welding conditions: air pressure 4 bar, cylinders ADN 20, amplitude $60 \%$ and $100 \%$.

\subsection{Influence of sample thickness}

The objective of this section is to investigate on the effect of sample thickness. To reach such a purpose, an experiment was designed to weld S1-S1 papers while varying the effective thickness of the welding assembly. S1-S1 papers were located in between layers of copy paper, the latter showing no weldability at all. The amount of copy paper layers was adapted to obtain a large range of sample thickness from $0.2 \mathrm{~mm}$ (reference paper only) to $2.0 \mathrm{~mm}$ (10 layers of copy paper on each side). S1$\mathrm{S} 1$ papers were always located at the middle of the paper stack. Samples were then welded using the cylinder tooling and the anvil $\mathrm{n}^{\circ} 2$, Figure 12 (de- tailed welding conditions). Results show that the mechanical performances of S1-S1 samples alone are quite bad, Figure $12(20 \mathrm{~N} / \mathrm{m})$. When the thickness increases, mechanical performances improve until reaching $250 \mathrm{~N} / \mathrm{m}$ which corresponds to the maximum level of adhesion obtainable for S1-S1 papers, Figures 9, 12. The peeling strength is stable between $0.5 \mathrm{~mm}$ and $1 \mathrm{~mm}$ and starts decreasing after $1 \mathrm{~mm}$. The fact that we used a stack of paper to increase sample thickness may introduce interfering phenomena leading to energy dissipation between layers. Thus, information brought by the samples $1 \mathrm{~mm}$ to $2 \mathrm{~mm}$-thick may not be relevant any more to solely discuss the effect of sample thickness.

One may also argue that because the structure of the paper stack changes with the thickness, the power response is expected to be different. Indeed, the associated $P_{m}$ and power curves are not identical even if close $P_{m}$ are obtained for the first 3 thicknesses (466 W, $526 \mathrm{~W}$, and $546 \mathrm{~W})$, Figure 12. It may explain in part the differences in welded joint performances. However, we also reproduced this experiment while adjusting the pressure in the cylinders to obtain a same $P_{m}$ for the first 3 thicknesses and we obtained the same results. It confirms that a thickness-related effect exists.

The thickness seems to be a parameter which can highly affect welding performances, especially when the total thickness gets close to the vibration amplitude. In particular, it seems that there is a critical thickness below which process efficiency is altered $(0.5 \mathrm{~mm}$ in our case). In such conditions, it
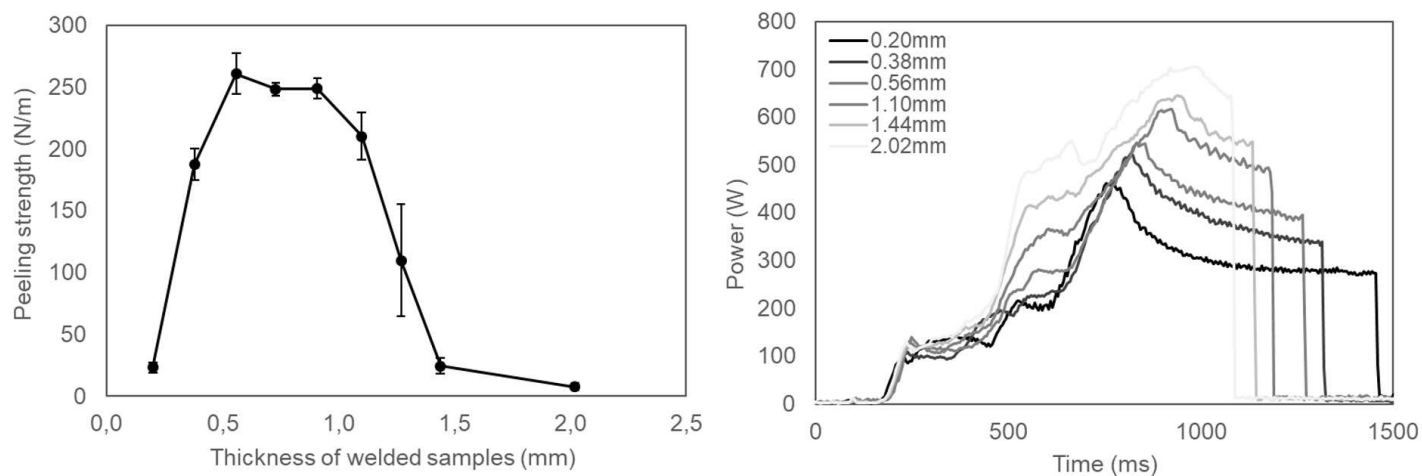

Figure 12. Peeling strength versus thickness (left) and related power curves (right) obtained while welding S1-S1 samples using the cylinder tooling and the anvil $n^{\circ} 2$. Sample thickness was adjusted by positioning S1-S1 papers in between several layers of copy paper. Welding conditions: air pressure 6 bar, cylinders ADN 20, amplitude $100 \%$, end condition $250 \mathrm{~J}$. 
appears difficult to convert mechanical vibrations into heat at the welding interface. In particular, we think that a lot of mechanical work is transmitted directly to the anvil. By artificially increasing the thickness of papers, heat generation at the welding interface is improved which explains why the peeling strength of S1-S1 papers drastically increases for identical welding conditions. This phenomenon might also exist for thermoplastic films, but it may be harder to observe because the better weldability of polymers tends to hide process-related effects.

In our case, we were able to compensate the thickness effect by modifying the welding area. As explained in the material section, two welding surfaces were considered in this study: a $20 \times 25 \mathrm{~mm}^{2}$ surface $\left(2 \mathrm{D}\right.$, anvil $\left.\mathrm{n}^{\circ} 2\right)$, and a $1 \mathrm{~mm}$-thick welding line of $25 \mathrm{~mm}\left(1 \mathrm{D}\right.$, anvil $\left.\mathrm{n}^{\circ} 1\right)$. The maximal performances obtainable for $\mathrm{S} 1-\mathrm{S} 1$ welded papers is about 250-300 N/m, Figure 9. However, the highest peeling strengths observed for 2D-weldings of S1-S1 samples without adjusting sample thickness were about $90 \mathrm{~N} / \mathrm{m}$, Table 4 . By switching to $1 \mathrm{D}$ weldings, we were able to obtain the expected performances. Our guess is that reducing the welding area (by about a factor of 20) and so increasing the pressure in the welded material has been able to compensate for the decrease in process efficiency induced by the low thickness. We also think that the thickness effect is a behavior that can be managed by other strategies such as the design of adapted acoustic parts or changing the working frequency. Such things should be explored further either experimentally or numerically. Tools allowing an estimation of the process efficiency could be of great value in this framework.

Nevertheless, thickness remains a critical point regarding the ultrasonic welding of papers. In packaging applications, it is frequent to work with thicknesses of $100 \mu \mathrm{m}$ or less. So far, this parameter was not so much reported in other works. As mentioned earlier, thicknesses below $100 \mu \mathrm{m}$ can lead to larger standard deviation [24]. Another thickness-related effect was observed when assembling by ultrasonic welding artificial leathers coated with polyvinyl chloride [25]. The performances were dependent on the residual thickness of the welded joint. The latter can be changed by modifying the welding pressure or by applying a static pressure before welding which tends to favor the flowing of polyvinyl chloride outside the welding zone. But it is far from the phenomenon identified in this study. The effect of thickness (from $20 \mu \mathrm{m}$ to $40 \mu \mathrm{m})$ on the welding performances was also investigated for the ultrasonic welding of Polyethylene/Polybutene-1 films (welding loads $400 \mathrm{~N}-$ $1200 \mathrm{~N}, 200 \mathrm{~mm}$-line weldings, vibration amplitude $30 \mu \mathrm{m})$ [26]. But no significant tendencies were observed as the maximum peel force release rate was found to be independent from the thickness of the peeled layer. However, it was reported that the ultrasonic process causes high standard deviation and low reproducibility of the peel behavior for the studied range of film thickness. Once again, it must be noted that the materials mentioned above have a very good weldability compared to ours which should tend to hide effects associated to sample thickness.

\subsection{Influence of other welding inputs}

The other input parameters (amount of energy, welding speed, post-welding load) do not have a high impact on the welding performances of the reference paper. Our guess is that they may affect the ultrasonic welding of papers but at a lower order of magnitude compared to force, power, and amplitude.

The end condition has a low impact on welding performances, Figure 11. Larger amounts of energy do not increase the peeling strength of welded papers for a given $P_{m}$. It is rather the opposite as prolonging the welding by increasing the energy condition tends to damage papers and so decrease their mechanical performances. Thus, it seems that the best end condition is no more energy that what is needed to trigger the power peak.

Changing the welding speed has not led to any differences in the peeling strength of welding papers. As mentioned earlier, the only critical point regarding this parameter is that it is limited while working with the cylinder tooling. More precisely, the combination welding speed-force must be considered. When the speed and/or the force are too high, the impact when horn and anvil come into contact is too strong and it can lead to machine damaging or controller default.

Post-welding loads were applied for shorter and longer times in preliminary studies $(0.1-1-10 \mathrm{~s})$ but no differences were observed regarding the me- 
chanical performances of welded papers. This parameter is known to be critical when welding thermoplastic polymers as too short post-load times may result in uncomplete interface consolidation. Though it is not the scope of this study, only the polyvinyl alcohol layer, which thickness is a few $\mu \mathrm{m}$, is involved in the welding of the reference paper. The establishment of adhesion is expected to come from a thermoplastic mechanism, i.e. polyvinyl alcohol melting and flowing when passing above its transition temperature. Considering the low volume of polymer involved and the low thickness of papers, heating and cooling in welded samples are expected to be very fast. Thus, post-welding loads may not be needed at all for the ultrasonic welding of papers.

\section{Conclusion}

The ultrasonic welding applied to papers is an extremely sensitive process. It is mainly due to the fact that papers are much harder to weld than thermoplastic polymers. It seems that paper only play a role of support for the coated layer which is the main element contributing to the development of adhesion at the welding joint. Thus, the successful ultrasonic welding of papers can be defined by a two-step condition: finding the optimized process parameters to efficiently convert acoustic vibration into interfacial heat, and finding the optimized coating properties to develop strong welded joints. As a consequence, the optimization of processing conditions alone is a mandatory step to ensure the good welding of papers. It confirms that it is really important to separate the contribution of process and materials considering the hybrid character of the welding.

Numerous process parameters have a strong impact on the mechanical performances of welded papers. Moreover, many of these parameters are intertwined meaning that it is possible to act either on machine parts or process control inputs to act on a same physical quantity. The most impactful parameters are vibration amplitude, power supplied by the high frequency generator, and paper thickness. In particular, the key parameter seems to be the power. It is a reliable indicator of the severity of the process which can be described as the amount of power per volume unit received at the welding interface. Power can be used to size and monitor the process which represents a high applicative interest. The simplest and most efficient way to control the peak power is to act on the welding load. Changing the vibration amplitude affects the reproducibility of the process. At last, the thickness of papers seems to be a major concern considering that a strong decrease in mechanical performances is observed when working with low thicknesses. This effect is attributed to a reduction of process efficiency triggered when the thickness of the welding assembly becomes too low.

Overall, the experimental strategy chosen in this study has been successful. A better understanding has been achieved by correlating the monitoring of process parameters to the properties of welded papers. The instrumented machine seems also to be a relevant and reliable tool to investigate on the weldability of papers. It will most likely be the scope of further studies.

\section{Acknowledgements}

The authors acknowledge the financial support of the French ANR (Agence National de la Recherche). The authors also thank all collaborators of the Ultracell ANR project for their contribution and in particular Sonimat for supplying the ultrasonic welding machine.

\section{References}

[1] H. Potente, Mater. Des. 1984, 5(5), 228. DOI: 10.1016/0261-3069(84)90032-3.

[2] M.N. Tolunay, P.R. Dawson, K.K. Wang, Polym. Eng. Sci. 1983, 23(13), 726. DOI:10.1002/pen.760231307.

[3] A. Benatar, R.V. Eswaran, S.K. Nayar, Polym. Eng. Sci. 1989, 26(23), 1689. DOI:10.1002/pen.760292311.

[4] A. Benatar, Z. Cheng, Polym. Eng. Sci. 1989, 26(23), 1699. DOI:10.1002/pen.760292312.

[5] Z. Zhang, X. Wang, Y. Luo, Z. Zhang, L. Wang, J. Thermoplast. Compos. Mater. 2010, 23, 647. DOI:10.1177/0892705709356493.

[6] S. Tutunjian, O. Eroglu, M. Dannemann, N. Modler, F. Fischer, J. Thermoplast. Compos. 
Mater. 2020, 33(11), 1569. DOI:10.1177/ 0892705719833108.

[7] I. Fernandez Villegas, Composites Part A 2014, 65, 27. DOI:10.1016/j.compositesa.2014.05.019.

[8] I. Fernandez Villegas, J. Thermoplast. Compos. Mater. 2015, 28(1), 66. DOI:10.1177/ 0892705712475015 .

[9] I. Fernandez Villegas, B. Valle Grande, H.E.N. Bersee, R. Benedictus, Compos. Interfaces 2015, 22(8), 717. DOI:10.1080/ 09276440.2015 .1053753$.

[10] A. Levy, S. Le Corre, N. Chevaugeon, A. Poitou, J. Theor. Appl. Mech. 2011, 30, 501. DOI:10.1016/j.euromechsol.2011.03.010.

[11] A. Levy, S. Le Corre, A. Poitou, E. Soccard, Int. J. Multiscale Comput. Eng. 2011, 9(1), 53.

[12] A. Levy, S. Le Corre, A. Poitou, International Journal of Material Forming 2014, 7, 39. DOI 10.1007/s12289-012-1107-6.

[13] B. Stamm, Ph.D. Thesis EPF Lausanne, Switzerland, 2005.

[14] B. Gfeller, M. Zanetti, M. Properzi, A. Pizzi, F. Pichelin, M. Lehmann, L. Delmotte, J. Adhes. Sci. Technol. 2003, 17(11), 1573. DOI:10.1163/156856103769207419.

[15] J.-M. Leban, A. Pizzi, S. Wieland, M. Zanetti, M. Properzi, F. Pichelin, J. Adhes. Sci. Technol. 2004, 18(6), 673. DOI:10.1163/ 156856104839310.

[16] C. Ganne-Chedeville, M. Properzi, A. Pizzi, J.M. Leban, F. Pichelin, Holzforschung 2006, 60, 434. DOI:10.1515/HF.2006.068.

[17] L. Delmotte, C. Ganne-Chedeville, J.M. Leban, A. Pizzi, F. Pichelin, Polym. Degrad. Stab.
2008, 93, 406. DOI:10.1016/j.polymdegradstab.2007.11.020.

[18] C. Ganne-Chedeville, M. Properzi, J.M. Leban, A. Pizzi, F. Pichelin, J. Adhes. Sci. Technol. 2008, 22, 761. DOI:10.1163/ $156856108 X 295392$.

[19] C. Ganne-Chédeville, G. Duchanois, A. Pizzi, J.-M. Leban, F. Pichelin, J. Adhes. Sci. Technol. 2008, 22, 1209. DOI:10.1163/ 156856108 X323688.

[20] S. Abbasion, J. Carmeliet, M. Sedighi Gilani, P. Vontobel, D. Derome, Holzforschung 2015, 69(7), 825. DOI:10.1515/hf-2014-0189.

[21] S. Abbasion, P. Moonen, J. Carmeliet, D. Derome, Holzforschung 2015, 69(7), 839. DOI:10.1515/hf-2014-0189.

[22] A. Regazzi, J. Viguie, B. Harthong, P. Dumont, D. Imbault, R. Peyroux, M. Rueff, Q. Charlier, D. Guerin, L. Leroy, M. Krouit, M. Petit-Conil, J. Mater. Sci. 2019, 54, 12938. DOI:10.1007/s10853-019-03763-7.

[23] F. Lionetto, M. Nicolas Morillas, S. Pappadà, G. Buccoliero, I. Fernandez Villegas, A. Maffezzoli, Composites Part A 2018, 104, 32. DOI 10.1016/j.compositesa.2017.10.021.

[24] J. Vogel, D. Grewell, M. Kessler, D. Drummer, M. Menacher, Polym. Eng. Sci. 2011, 51(6), 1059. DOI:10.1002/pen.21919.

[25] S. Volkov, I. Garanin, Y. Khopolov, Welding International 1998, 12(1), 76. DOI:10.1080/ 09507119809448974.

[26] M. Nase, S. Bach, A. Zankel, J.P. Majschak, W. Grellmann, J. Appl. Polym. Sci. 2013, 130, 383. DOI:10.1002/app.39171.

Received in final form: May $20^{\text {th }} 2021$ 